Grzegorz Bartoszewicz

Poznan School of Logistics

e-mail: grzegorz.bartoszewicz@wsl.com.pl

Maciej Wdowicz

Poznan School of Logistics

e-mail: maciej.wdowicz@ test.pl

\title{
AUTOMATION OF THE PROCESS OF REPORTING THE COMPLIANCE OF THE PRODUCTION PLAN WITH ITS EXECUTION BASED ON INTEGRATION OF SAP ERP SYSTEM IN CONNECTION WITH EXCEL SPREADSHEET AND VBA \\ APPLICATION
}

\begin{abstract}
Background: The ERP systems in spite of its huge functionalities cannot realize all user needs and requirements especially concerning intelligent business analysis and reporting (BI). Therefore it is necessary to find out new, simple and flexible methods and techniques to expand their functionality and report facilities. In this chapter we propose the new method of production process analysis, its automation and visualization, based on integration of the SAP ERP/PP module with Excel spreadsheet and VBA application. This approach is very useful for managerial decision making process in production planning and control.
\end{abstract}

Methods: Basing on the previous developed configuration methods we have proposed an integration approach, connecting data base resources from SAP ERP system with Excel spreadsheet and VBA application.

Results: The new application called FTP Report allows to prepare The compliance report of the production plan with its implementation within the prescribed period. It automatizes the process of data migration from SAP ERP Production Planning module and then supports intelligent data analysis and finally data reporting.

Conclusions: The new redesigned and implemented process of data migration and analyzing is faster and more flexible and allows to speed up the whole process of complex analytical report edition from 2 hours to 5 min.

Bartoszewicz G, Wdowicz M., Automation of The Process of Reporting the Compliance of the Production Plan with Its Execution Based on Integration of Sap ERP System in Connection with Excel Spreadsheet and Vba Application [in:] Adamczak M. et al., Digitalization of Supply Chains, Spatium, Radom 2019, p. 101-116.

https://doi.org/10.17270/B.M.978-83-66017-86-3.8 
Keywords: SAP ERP/PP enhancements, Production Planning and Execution, Data Reporting, Business Process Analysis, Production Processes Integration, Production Process Reengineering (PPR), VBA application.

\section{INTRODUCTION}

The essence of the article is to propose a method and a tool for automating the process of reporting and compliance analysis of the production plan with its executing. The tool should be easy to operation without any knowledge of programming in a complex production environment of SAP ERP 6.0 system [Auksztol, Balwierz and Chomuszko 2011, Schulz 2017]. The Program should significantly reduce the time needed to prepare the Report and prevent it from generating a human errors in the data retrieval and process analysis. Therefore we can treat this activities as a production process strategy PPIS and a part of BPR (Business Process Reengineering), [Akhatar 2015, Erwan 2017, Dickersbach and Keller 2011].

The program called FTP Report (Follow The Plan Report) that was created for this work is based on Microsoft Excel macro-enabled application and code written in Visual Basic for Application [Alexander and Kusleika 2016]. This tool automates the process of retrieving and analyzing data from the system SAP ERP PP (Production Planning module), needed to create a compliance report within the specified period, using SAP transactions - COOISPI and MB51. These system transactions are crucial for retrieving data into the Report.

\section{SAP ERP PRODUCTION PLANNING MODULE}

\section{Production Planning And Execution With SAP ERP PP}

The production execution process in SAP ERP begins when the planned production order (Planned Order) is transformed into a Process Order. The first one listed is in most cases generated automatically by a demand based PIR system (Planned Independent Requirement). When needed, the production planner can also create a planned order manually (using the SAP MD11 transaction). At the time of conversion to Process Order, the system ultimately checks finally, based on the product structure BOM (Bill of Material), whether all materials needed to complete the product are in stock. The user can additionally choose which batches of each component should be allocate to the order. When everything is ready, the status of the Process

Bartoszewicz G, Wdowicz M., Automation of The Process of Reporting the Compliance of the Production Plan with Its Execution Based on Integration of Sap ERP System in Connection with Excel Spreadsheet and Vba Application [in:] Adamczak M. et al., Digitalization of Supply Chains, Spatium, Radom 2019, p. 101-116. https://doi.org/10.17270/B.M.978-83-66017-86-3.8 
Order is changed on REL (Released) and a new batch is assigned to a finished product. At this point, the materials assigned into the order can be delivered to the indicated Work Center and start production, which is done according to the data in the Routings [Akhtar 2015, Chapman 2006, Dickersbach and Keller 2011, Schulz 2017].

When the production process is completed, the order is confirmed, and any movements and material consumption are already posted during its lifetime. The order receives the status DLV (delivered), and the finished product is received and delivered to the designated place. Most often at the end of the month prior to the settlement of orders, to each of them is given the status of TECO (technically completed), in order to calculate the production deviations by the relevant department. The production planning schema in SAP ERP is presented in Figure 1.

\section{PRODUCTION PLANNING PROCESS}

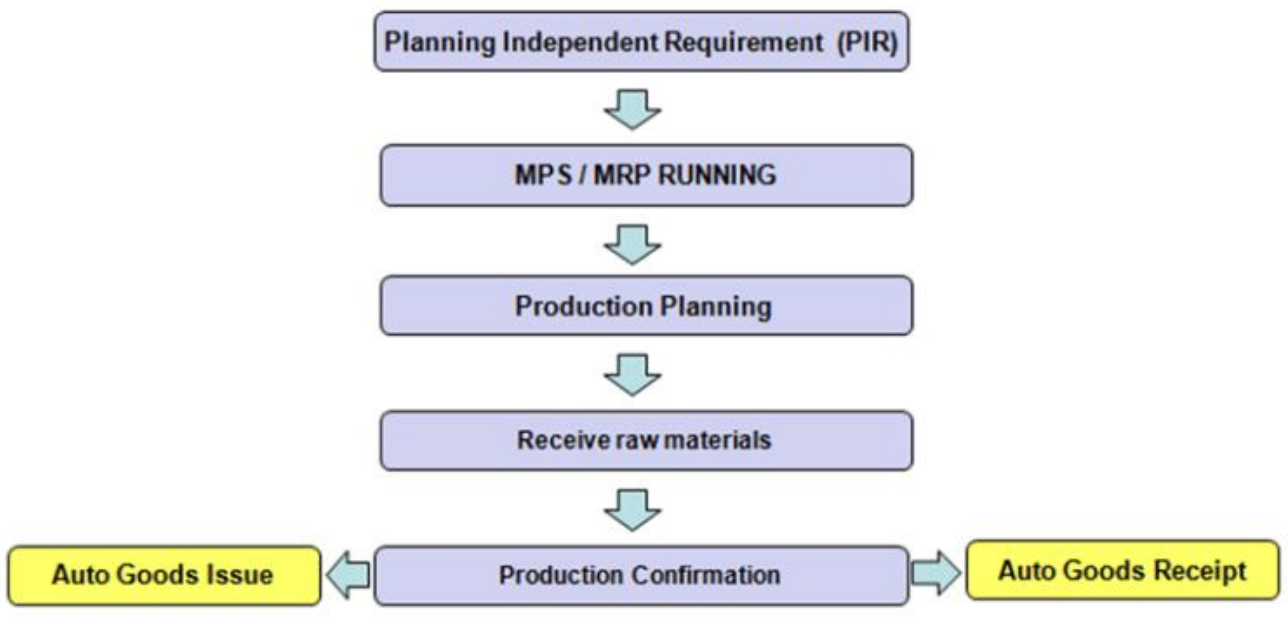

Fig. 1. Production planning scheme in SAP ERP.

Source: [Introduction-SAP PP n,d.].

\section{Transactions In Sap Erp For Data Retrieving From Production Schedule (Cooispi) And Tracking Material Movements (Mb51)}

The COOISPI transaction is described in SAP as Production Order Information System. Using it, you can get all the information about planned and process production orders, which is a large database for users planning production. To invoke COOISPI, you must use the SAP GUI to type the transaction name in the Menu.

Bartoszewicz G, Wdowicz M., Automation of The Process of Reporting the Compliance of the Production Plan with Its Execution Based on Integration of Sap ERP System in Connection with Excel Spreadsheet and Vba Application [in:] Adamczak M. et al., Digitalization of Supply Chains, Spatium, Radom 2019, p. 101-116.

https://doi.org/10.17270/B.M.978-83-66017-86-3.8 
The selection of columns and their order in the COOISPI transaction is fully selectable by the user. You can also easily send this data to a Microsoft Excel spreadsheet. The file generated by this method is shown in Figure 2.

Transaction MB51 is a useful tool in SAP ERP, mainly used to track the movement of materials in the system. In the software developed by SAP, all material movements are saved in the relevant documents. This makes it possible to track the history of material movements [MB51 n.d.].

\begin{tabular}{|c|c|c|c|c|c|c|c|}
\hline A & B & C & D & $E$ & $\mathrm{~F}$ & G & H \\
\hline Order & |Material & \begin{tabular}{|l} 
Item \\
comp \\
onent \\
list
\end{tabular} & Requirement date & \begin{tabular}{|l} 
Requirement \\
quantity \\
(EINHEIT)
\end{tabular} & $\begin{array}{l}\text { Quantity } \\
\text { withdrawn } \\
\text { (EINHEIT) }\end{array}$ & $\begin{array}{l}\text { Base Unit of Measure } \\
(=\text { EINHEIT) }\end{array}$ & $\begin{array}{l}\text { Open Quantity } \\
\text { (EINHEIT) }\end{array}$ \\
\hline$2 \longdiv { 2 0 8 4 3 6 }$ & 700695 & 0010 & $23 / 03 / 2016$ & 296.800 & 0.000 & $\mathrm{HL}$ & 296.800 \\
\hline 3208436 & 200033 & 0050 & $23 / 03 / 2016$ & 0.556 & 0.000 & KG & 0.556 \\
\hline 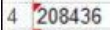 & 201200 & 0060 & $23 / 03 / 2016$ & 1.113 & 0.000 & KGA & 1.113 \\
\hline$5 \longdiv { 2 0 8 4 3 6 }$ & 200005 & 0070 & $23 / 03 / 2016$ & 0.890 & 0.000 & $K G$ & 0.890 \\
\hline 62208436 & 200004 & 0080 & $23 / 03 / 2016$ & 9.275 & 0.000 & KG & 9.275 \\
\hline 7208436 & 200003 & 0090 & $23 / 03 / 2016$ & 37.100 & 0.000 & $K G$ & 37.100 \\
\hline 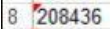 & 202495 & 0110 & $23 / 03 / 2016$ & 15.397 & 0.000 & $K G$ & 15.397 \\
\hline$9 \longdiv { 2 0 8 4 3 6 }$ & 202333 & 0120 & $23 / 03 / 2016$ & 4.823 & 0.000 & KG & 4.823 \\
\hline 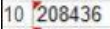 & 700071 & 0130 & $23 / 03 / 2016$ & 74.200 & 0.000 & L & 74.200 \\
\hline $11 / 211443$ & 700695 & 0010 & $23 / 03 / 2016$ & 333.600 & 0.000 & $\mathrm{HL}$ & 333.600 \\
\hline $12 / 211443$ & 200033 & 0050 & $23 / 03 / 2016$ & 0.625 & 0.000 & KG & 0.625 \\
\hline 13211443 & 201200 & 0060 & $23 / 03 / 2016$ & 1.251 & 0.000 & KGA & 1.251 \\
\hline $14 " 211443$ & 200005 & 0070 & $23 / 03 / 2016$ & 1.001 & 0.000 & KG & 1.001 \\
\hline $15 \quad 211443$ & 200004 & 0080 & $23 / 03 / 2016$ & 10.425 & 0.000 & $K G$ & 10.425 \\
\hline $16^{\prime 2} 211443$ & 200003 & 0090 & $23 / 03 / 2016$ & 41.700 & 0.000 & $K G$ & 41.700 \\
\hline $17^{2} 211443$ & 202495 & 0110 & $23 / 03 / 2016$ & 17.305 & 0.000 & $K G$ & 17.305 \\
\hline 18211443 & 202333 & 0120 & $23 / 03 / 2016$ & 5.421 & 0.000 & KG & 5.421 \\
\hline 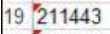 & 700071 & 0130 & $23 / 03 / 2016$ & 83.400 & 0.000 & $L$ & 83.400 \\
\hline
\end{tabular}

Fig. 2. COOISPI transaction output saved as an Excel sheet.

Source: [COOISPI n.d.].

The MB51 transaction like COOISPI can be personalized by saving your own settings as a ready Layout, making it easier to automate operations. The sample result of this transaction is shown in Figure 3, where the user follows the movement history for exemplary material 153. The MB51 report can be successfully exported to a Microsoft Excel spreadsheet file by rightclicking on any record and selecting the "Spreadsheet" option.

Bartoszewicz G, Wdowicz M., Automation of The Process of Reporting the Compliance of the Production Plan with Its Execution Based on Integration of Sap ERP System in Connection with Excel Spreadsheet and Vba Application [in:] Adamczak M. et al., Digitalization of Supply Chains, Spatium, Radom 2019, p. 101-116. https://doi.org/10.17270/B.M.978-83-66017-86-3.8 


\begin{tabular}{|c|c|c|c|c|c|c|c|c|c|}
\hline Mate & ent $L$ & ist & & & & & & & \\
\hline 144 & 吕守 & 色 & f15 & & 染 & & & & \\
\hline$[153$ & $\partial_{1011}$ & 1082 & 311 & & 4900007369 & 2 & 27.01 .2016 & $1.000,000$ & KG \\
\hline 153 & 1011 & 1082 & 311 & & 4900007369 & 1 & 27.01 .2016 & $1.000,000$ & KG \\
\hline 153 & 1011 & 1082 & 701 & & 4900007370 & 2 & 31.12 .2015 & 900,000 & KG \\
\hline
\end{tabular}

Fig. 3. MB51 transaction output for exemplary material 153.

Source: [MB51 n.d.].

\section{FTP report creation process}

By exporting data from SAP ERP COOISPI and MB51 transactions to an Excel workbook, an user can make a fully validated compliance report of the production plan with its execution (CROPPE). This kind of Report called the FTP Report is divided into two basic parts: plan and execution. The following elements will be required to prepare the plan:

- Data dump Order Headers of the COOISPI transaction - containing among others: Production order numbers, Finished product numbers, and date of orders;

- Data dump Operations of the COOISPI transaction- containing among others Production lines (from Work Center) on which the individual manufacturing operations are carried out.

Bartoszewicz G, Wdowicz M., Automation of The Process of Reporting the Compliance of the Production Plan with Its Execution Based on Integration of Sap ERP System in Connection with Excel Spreadsheet and Vba Application [in:] Adamczak M. et al., Digitalization of Supply Chains, Spatium, Radom 2019, p. 101-116.

https://doi.org/10.17270/B.M.978-83-66017-86-3.8 


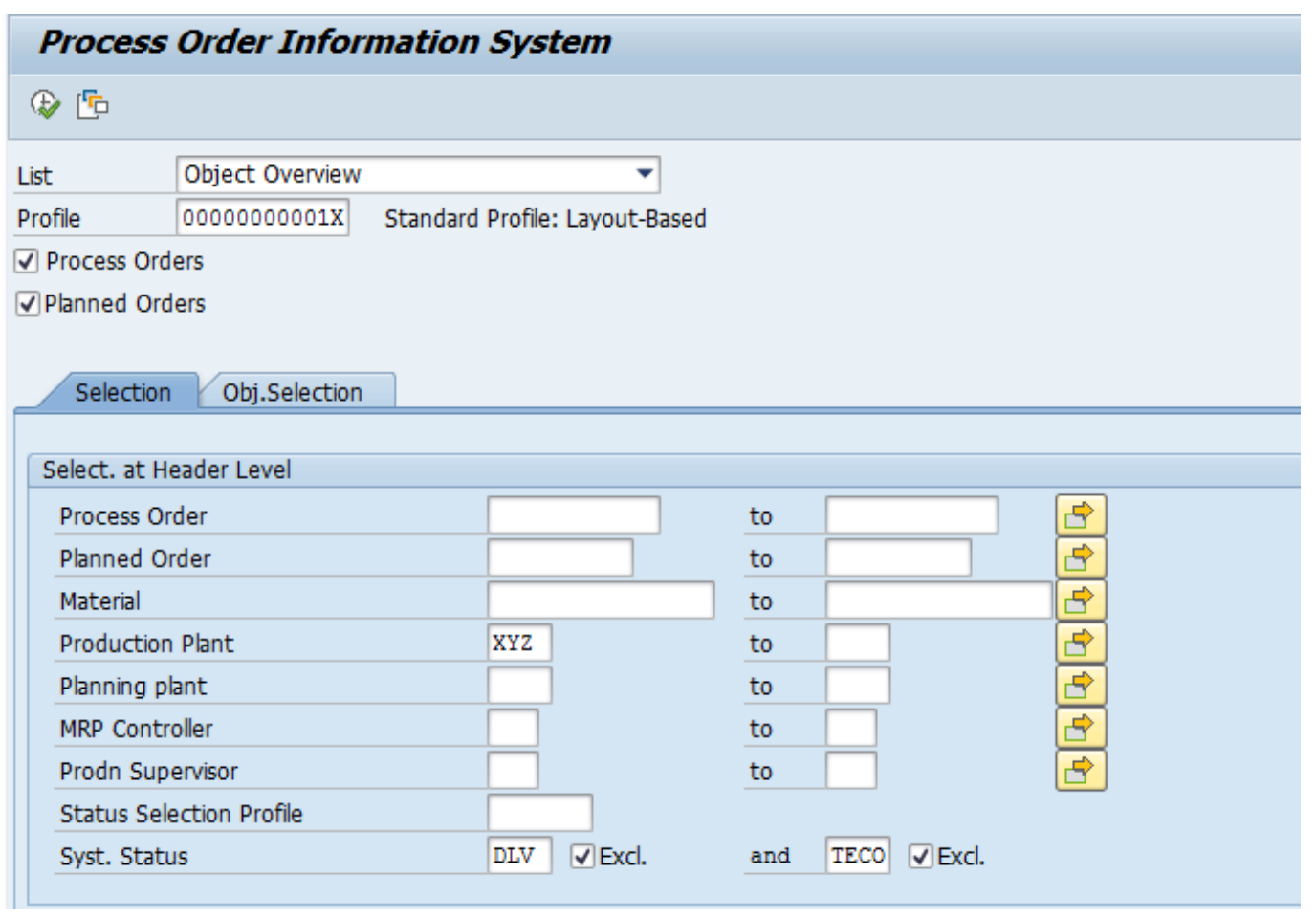

Fig. 4. COOISPI transaction with supplemented data.

Source: Screenshot from SAP ERP 6.0 system.

After preparing the production plan, you must wait until the end of its duration and then proceed to download the data from SAP ERP necessary to describe production execution. The first stage is very much like the preparation of the production plan described above. You should also retrieve a dump of the Order Headers and Operations of transaction COOISPI for the Object Overview variant (Figure 4). In the System Status field, should be included (as Exclude option) an orders with the DLV (delivered) and TECO (technically completed) status, because they will be the predominating part of the records needed to create the execution report, so they cannot be omitted. The second change relative to the plan download process will be selection of the time range in reference to other fields. In a case of a plan, this is a Basic Start Date, but the Actual Finish Date will be completed for execution depending on the accepted period of settlement of orders.

To speed up data download from the SAP ERP system and their automatic recalculation and formatting, SAP Script Recorder and Microsoft Excel are used in the FTP Report

Bartoszewicz G, Wdowicz M., Automation of The Process of Reporting the Compliance of the Production Plan with Its Execution Based on Integration of Sap ERP System in Connection with Excel Spreadsheet and Vba Application [in:] Adamczak M. et al., Digitalization of Supply Chains, Spatium, Radom 2019, p. 101-116. https://doi.org/10.17270/B.M.978-83-66017-86-3.8 
application. This makes the process of creating a report much shorter and minimize the risk of human errors.

\section{Presentation of the FTP report application}

The FTP Report application allows in a very accessible way and in a short time to prepare a compliance report of the production plan with its execution (CROPPE) and indicate possible causes of non-compliance. Implementation of such a Report and analysis is an important part of PPR (Production Process Reengineering), strategy [Erwan 2017, Akhtar 2015, Dickersbach and Keller 2011]. The scheme for preparing FTP Report is shown in Figure 5.

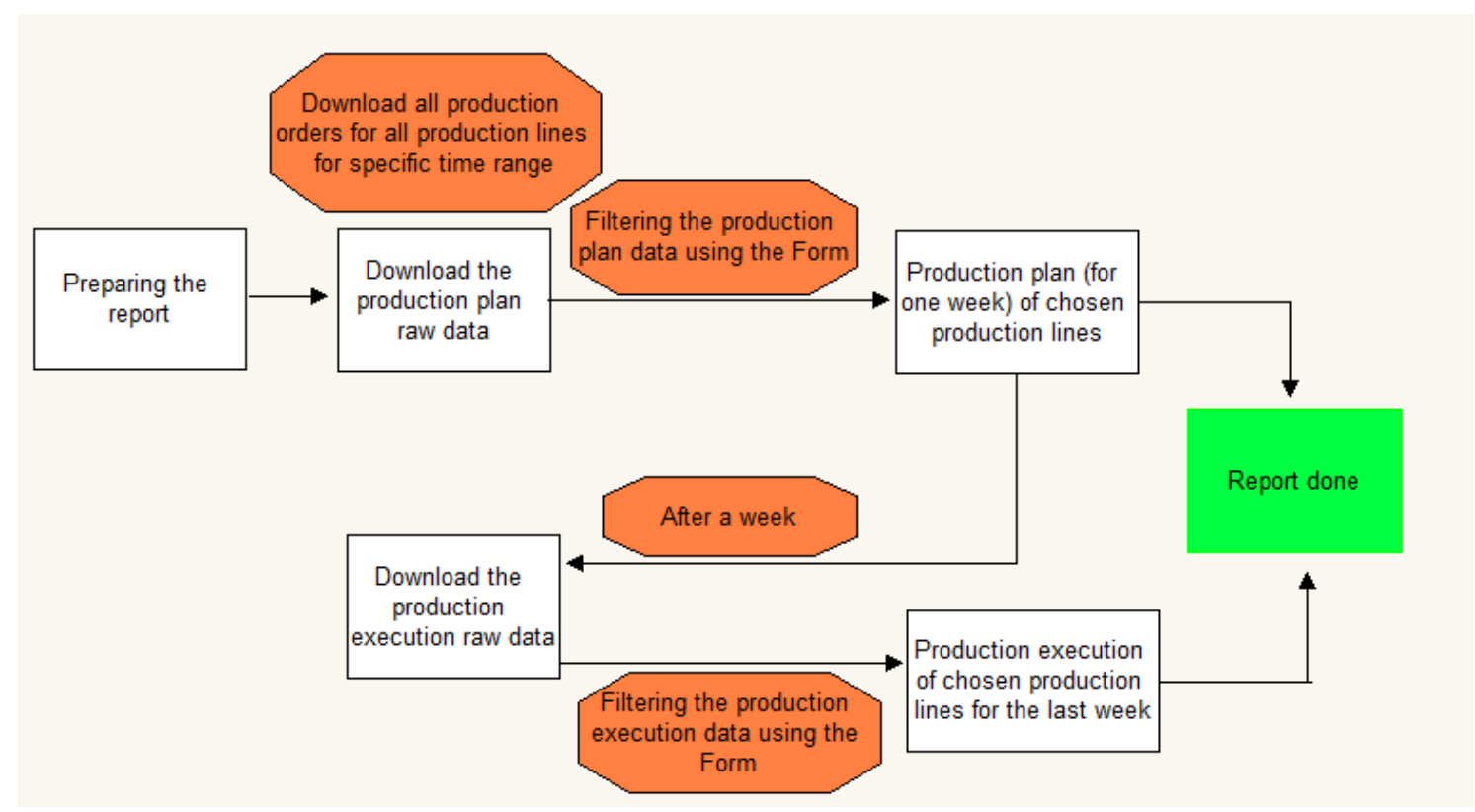

Fig. 5. The model of CROPPE Report creation.

Source: own elaboration.

\section{Download production plan from SAP ERP system}

The process of preparing the CROPPE Report should begin by picking up the production plan from SAP ERP using the COOISPI transaction. For this purpose, the FTP Report application implements the macro-coupled buttons, placed in the Excel tab "1. PLAN PANEL", which is presented in Figure 6.

Bartoszewicz G, Wdowicz M., Automation of The Process of Reporting the Compliance of the Production Plan with Its Execution Based on Integration of Sap ERP System in Connection with Excel Spreadsheet and Vba Application [in:] Adamczak M. et al., Digitalization of Supply Chains, Spatium, Radom 2019, p. 101-116.

https://doi.org/10.17270/B.M.978-83-66017-86-3.8 


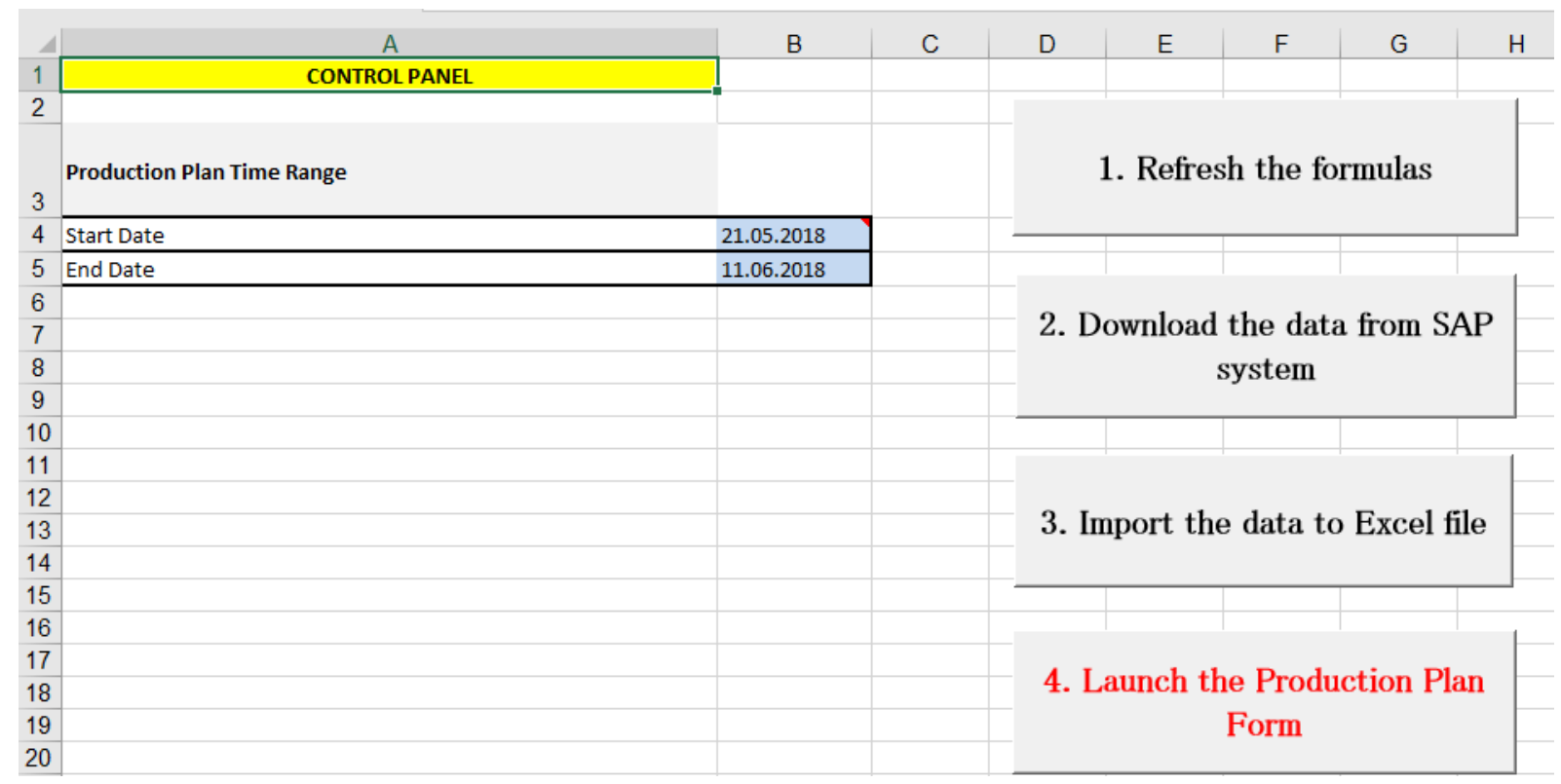

Fig. 6. Excel tab "1. Plan Panel" of the FTP Report application - download of the production plan from COOISPI.

Source: own elaboration.

In cells B4 and B5, the formulas are placed respectively, today's Day ("Start data") and the day in 3 weeks ("End data"). Both of these dates will be the scope for which the user retrieves the production plan from the COOISPI transaction. To do this, press the button "2. Download the data from SAP system", coupled with a macro called "Download data base".

The output is the spreadsheet shown in Figure 7. It contains data extracted from the COOISPI transaction: order number, material code, production line and exact planned start and end dates of the order. To copy the downloaded data to the FTP Report application, press the button shown in Figure 6: "3. Import the data to Excel file", which will run a macro to copy the cells appropriately formatting them.

Bartoszewicz G, Wdowicz M., Automation of The Process of Reporting the Compliance of the Production Plan with Its Execution Based on Integration of Sap ERP System in Connection with Excel Spreadsheet and Vba Application [in:] Adamczak M. et al., Digitalization of Supply Chains, Spatium, Radom 2019, p. 101-116. https://doi.org/10.17270/B.M.978-83-66017-86-3.8 


\begin{tabular}{|c|c|c|c|c|c|c|c|c|c|c|c|}
\hline 4 & A & c & $\mathrm{E}$ & $\mathrm{F}$ & $\mathrm{H}$ & 1 & J & $\mathrm{K}$ & L & M & $\mathrm{N}$ \\
\hline 1 & Order & Material Description & Resource & $\left|\begin{array}{l}\text { Work center } \\
\text { description }\end{array}\right|$ & $\begin{array}{c}\text { Latest start } \\
\text { time }\end{array}$ & Latest start date & \begin{tabular}{|l} 
Latest finish \\
time
\end{tabular} & Latest finish date & Basic Start Date & Basic finish date & $\begin{array}{l}\text { Operation } \\
\text { Quantity } \\
\text { (MEINH) }\end{array}$ \\
\hline 2 & 3000390696 & PRODUKT 18 & SK-X5 & LINIA X5 & $05: 16: 08$ & $2018-05-21$ & $10: 34: 13$ & 2018-05-21 & $2018-05-21$ & $2018-05-25$ & 1000 \\
\hline 3 & 3000389355 & PRODUKT 25 & SK-X5 & LINIA X5 & $10: 34: 13$ & 2018-05-21 & 12:07:05 & 2018-05-21 & 2018-05-21 & $2018-05-28$ & 192 \\
\hline 4 & 3000389356 & PRODUKT 24 & SK-X5 & LINIA X5 & $12: 07: 05$ & $2018-05-21$ & $16: 11: 57$ & 2018-05-21 & 2018-05-21 & $2018-05-28$ & 700 \\
\hline 5 & 3000384387 & PRODUKT 61 & SK-X5 & LINIA X5 & $16: 11: 57$ & $2018-05-21$ & $18: 16: 49$ & $2018-05-21$ & $2018-05-21$ & $2018-05-28$ & 700 \\
\hline 6 & 3000391906 & PRODUKT 32 & SK-X4 & LINIA X4 & 07:34:30 & $2018-05-21$ & 19:39:04 & $2018-05-21$ & 2018-05-21 & 2018-06-07 & 32500 \\
\hline 7 & 3000385003 & PRODUKT 35 & SK-X5 & LINIA X5 & $18: 16: 49$ & $2018-05-21$ & $20: 22: 01$ & $2018-05-21$ & 2018-05-21 & $2018-05-28$ & 705 \\
\hline 8 & 3000391227 & PRODUKT 16 & SK-X2 & LINIA X2 & $12: 03: 00$ & $2018-05-21$ & $20: 38: 33$ & 2018-05-21 & $2018-05-21$ & 2018-06-01 & 3800 \\
\hline 9 & 3000391902 & PRODUKT 30 & SK-X3 & LINIAX3 & $14: 00: 00$ & $2018-05-21$ & $00: 27: 26$ & $2018-05-22$ & 2018-05-21 & 2018-06-04 & 15354 \\
\hline 10 & 3000391639 & PRODUKT 67 & SK-X1 & LINIAX1 & $22: 00: 00$ & $2018-05-21$ & 02:10:04 & $2018-05-22$ & 2018-05-21 & 2018-06-04 & 5000 \\
\hline 11 & 3000391907 & PRODUKT 78 & SK-X4 & LINIAX4 & $19: 39: 04$ & 2018-05-21 & $02: 23: 00$ & 2018-05-22 & 2018-05-21 & 2018-06-08 & 14650 \\
\hline 12 & 3000392819 & PRODUKT 17 & SK-X3 & LINIAX3 & $00: 27: 26$ & 2018-05-22 & $02: 30: 22$ & 2018-05-22 & 2018-05-22 & 2018-06-04 & 396 \\
\hline 13 & 3000391228 & PRODUKT 97 & SK-X2 & LINIAX2 & $20: 38: 33$ & 2018-05-21 & $03: 27: 34$ & $2018-05-22$ & 2018-05-21 & 2018-06-04 & 3984 \\
\hline 14 & 3000392818 & PRODUKT 1 & SK-X3 & LINIAX3 & $02: 30: 22$ & $2018-05-22$ & 04:03:37 & $2018-05-22$ & 2018-05-22 & 2018-06-04 & 430 \\
\hline 15 & 3000391638 & PRODUKT 80 & SK-X1 & LINIAX1 & $11: 34: 51$ & $2018-05-21$ & $04: 52: 23$ & $2018-05-22$ & $2018-05-21$ & 2018-06-04 & 25000 \\
\hline 16 & 3000391801 & PRODUKT 32 & SK-X2 & LINIAX2 & $03: 27: 34$ & $2018-05-22$ & 06:07:18 & $2018-05-22$ & 2018-05-22 & 2018-06-04 & 960 \\
\hline 17 & 3000388657 & PRODUKT 38 & SK-X5 & LINIAX5 & $20: 22: 01$ & 2018-05-21 & $06: 20: 49$ & $2018-05-22$ & $2018-05-21$ & $2018-05-28$ & 14400 \\
\hline 18 & 3000393368 & PRODUKT 33 & SK-X3 & LINIAX3 & 04:03:37 & $2018-05-22$ & 07:53:10 & $2018-05-22$ & $2018-05-22$ & 2018-06-04 & 2880 \\
\hline 19 & 3000391683 & PRODUKT 21 & SK-X1 & LINIAX1 & $02: 10: 04$ & $2018-05-22$ & 08:08:06 & $2018-05-22$ & $2018-05-22$ & $2018-06-06$ & 19000 \\
\hline 20 & 3000394652 & PRODUKT 5 & SK-X2 & LINIA X2 & $06: 07: 18$ & $2018-05-22$ & 09:03:23 & $2018-05-22$ & $2018-05-22$ & 2018-06-04 & 1104 \\
\hline
\end{tabular}

Fig. 7. The data base of orders for production planning - Excel tab „2. BAZA PLAN”.

Source: own elaboration.

Finally, you will still need to indicate which production lines and dates will be included into the report. To do this, start the macro "4. Launch the Production Plan Form", which will display the form shown in Figure 8. The base of the production plan downloaded from COOISPI will always be the same as in tab "2. BASE PLAN" (Figure 7). By contrast, using the form (Figure 8) the user can filter the items from the base after production lines and dates, and then save them in a separate tab "3. PLAN TO FTP", which will be the input data for calculation the compliance of the execution and the production plan. This gives a lot of flexibility for the user, as it will be possible to add a missed production line or change the date range during an ongoing billing period. However, remember to refresh your data periodically, i.e. download a dump from COOISPI to have correct and accurate information (e.g. after resetting schedules).

Bartoszewicz G, Wdowicz M., Automation of The Process of Reporting the Compliance of the Production Plan with Its Execution Based on Integration of Sap ERP System in Connection with Excel Spreadsheet and Vba Application [in:] Adamczak M. et al., Digitalization of Supply Chains, Spatium, Radom 2019, p. 101-116.

https://doi.org/10.17270/B.M.978-83-66017-86-3.8 


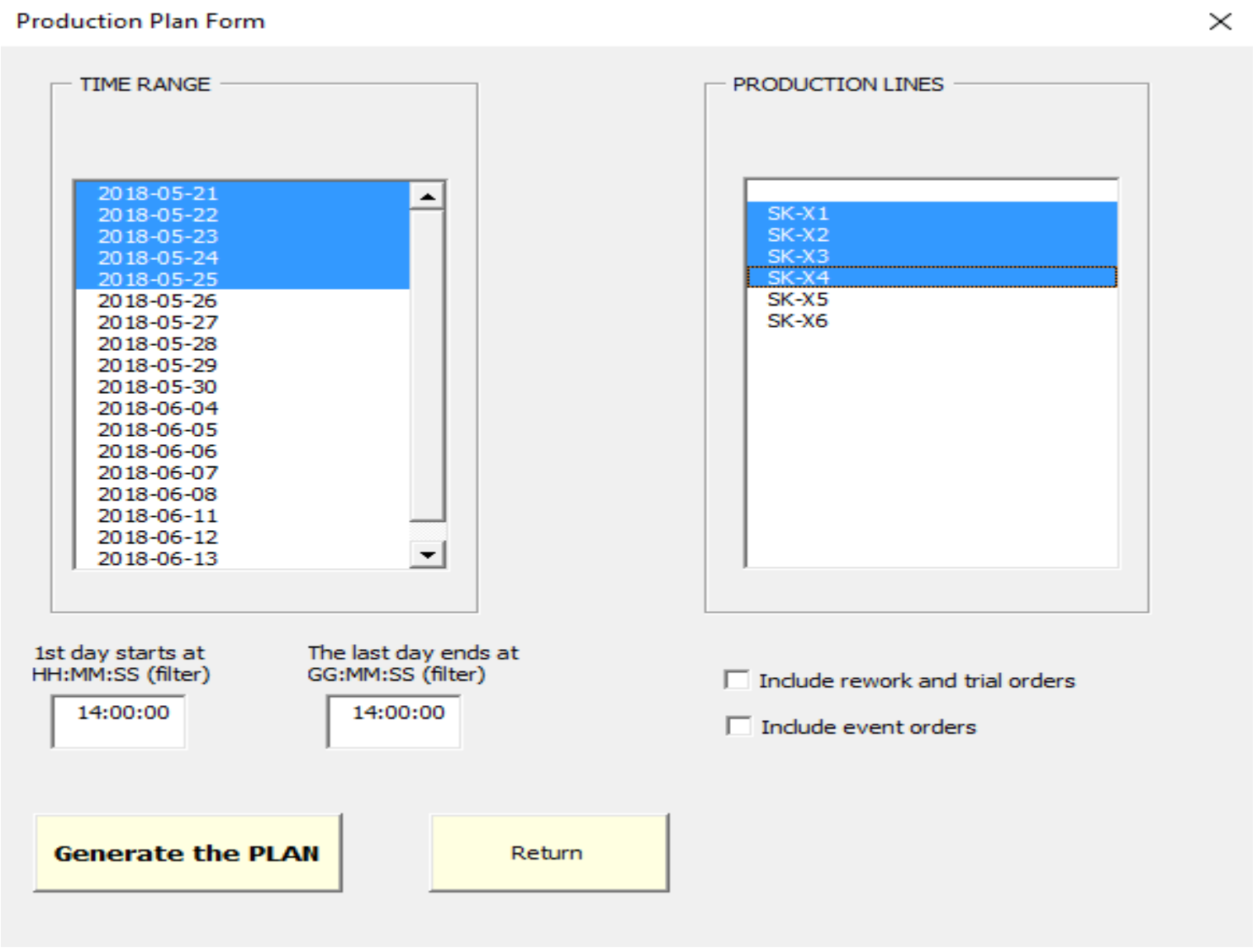

Fig. 8. Production plan form that filters data from data base (2. BAZA PLAN).

Source: own elaboration.

\section{Download production plan execution from SAP ERP system}

In accordance with the process described more broadly in Chapter 2, when the accepted settlement period of the production plan has passed, you must proceed to download from the SAP ERP production execution, data within the planned period. To do this, you will need the following data dumps:

- 1. COOISPI (orders with status "Delivered"),

- 2. COOISPI (dump containing all Process Orders included in dump 1 and corresponding Planned Orders),

- 3. MB51 (settled with an accuracy to 1 pallet the execution of orders from dump 1).

Data dumps must be performed in the sequence indicated above. The first file will indicate to the user the orders that were executed during the accepted billing period. At the time of the

Bartoszewicz G, Wdowicz M., Automation of The Process of Reporting the Compliance of the Production Plan with Its Execution Based on Integration of Sap ERP System in Connection with Excel Spreadsheet and Vba Application [in:] Adamczak M. et al., Digitalization of Supply Chains, Spatium, Radom 2019, p. 101-116. https://doi.org/10.17270/B.M.978-83-66017-86-3.8 
production plan dump, it is likely that some of the orders included in the screenshot were not yet converted from the Planned Order into the Process Order. For a verb to be executed, it must be converted into Process Order, so it may happen that the same order could actually be in the production plan as Planned Order, while production was performed as a Process Order. Therefore, the dump No 2 is required, which assigns to each Process order a corresponding Planned Order (from which it was previously converted). The third dump in turn allows you to get data about the execution of the orders not yet completed (without the status "Delivered"), with the accuracy of the execution to 1 pallet. This allows the user to determine how much of the products have been left to pack. There may be a situation where sufficient quantity has already been produced to consider the order to be included in the Report (e.g. $90 \%$ of the packaged volume).

After downloading all the screenshots described, which was automated analogously as in the case of the production plan base, in the file FTP Report filled up with data will be Excel tab "5. Orders done", as presented in Figure 9.

This sheet contains data about the order number, the material number, the time and date of the last pallet sentence, and the aggregated order quantity. It also includes the production line information and the planned order number from which it was converted to a process order. Similarly to the production plan base, the user can filter the production plan execution base using a special form (as presented in Figure 8).

The data that were filtered by both the production plan database and the execution base forms are input to calculate the FTP Report.

Bartoszewicz G, Wdowicz M., Automation of The Process of Reporting the Compliance of the Production Plan with Its Execution Based on Integration of Sap ERP System in Connection with Excel Spreadsheet and Vba Application [in:] Adamczak M. et al., Digitalization of Supply Chains, Spatium, Radom 2019, p. 101-116.

https://doi.org/10.17270/B.M.978-83-66017-86-3.8 


\begin{tabular}{|c|c|c|c|c|c|c|c|c|}
\hline 4 & A & C & D & G & $\mathrm{H}$ & $J$ & M & N \\
\hline & Order & Material description & Order Type & Actual finish & Actual finish date & Delivered & Resource & Planned Order \\
\hline 1 & $\checkmark$ & $\nabla$ & $\nabla$ & $\checkmark$ & $\nabla$ & $\checkmark$ & $\checkmark$ & $\checkmark$ \\
\hline 2 & 3000392037 & PRODUKT 88 & ZP01 & $03: 16: 54$ & $2018-05-21$ & 3217 & SK-X3 & 102147224 \\
\hline 3 & 3000392026 & PRODUKT 81 & ZP01 & $03: 18: 44$ & $2018-05-21$ & 704 & SK-X5 & 103610391 \\
\hline 4 & 3000392663 & PRODUKT 21 & ZP01 & $05: 05: 51$ & $2018-05-21$ & 13800 & SK-X4 & 105979545 \\
\hline 5 & 3000392819 & PRODUKT 17 & ZP01 & $10: 43: 26$ & $2018-05-21$ & 405 & SK-X3 & 102022127 \\
\hline 6 & 3000391226 & PRODUKT 27 & ZP01 & $11: 03: 43$ & $2018-05-21$ & 11655 & SK-X2 & 103959503 \\
\hline 7 & 3000390696 & PRODUKT 18 & ZP01 & $14: 26: 55$ & $2018-05-21$ & 1002 & SK-X5 & 100219869 \\
\hline 8 & 3000389355 & PRODUKT 25 & ZP01 & $16: 53: 23$ & $2018-05-21$ & 192 & SK-X5 & 99793382 \\
\hline 9 & 3000391638 & PRODUKT 80 & ZP01 & $17: 28: 27$ & $2018-05-21$ & 24200 & SK-X1 & 99060577 \\
\hline 10 & 3000389356 & PRODUKT 24 & ZP01 & $20: 52: 14$ & $2018-05-21$ & 725 & SK-X5 & 99788530 \\
\hline 11 & 3000391906 & PRODUKT 32 & ZP01 & $21: 16: 06$ & $2018-05-21$ & 32958 & SK-X4 & 99923642 \\
\hline 12 & 3000391902 & PRODUKT 30 & ZP01 & $21: 19: 47$ & $2018-05-21$ & 15439 & SK-X3 & 102490012 \\
\hline 13 & 3000391639 & PRODUKT 67 & ZP01 & $22: 43: 55$ & $2018-05-21$ & 5249 & SK-X1 & 98899123 \\
\hline 14 & 3000391227 & PRODUKT 16 & ZP01 & $22: 48: 10$ & $2018-05-21$ & 3345 & SK-X2 & 102152087 \\
\hline 15 & 3000384387 & PRODUKT 61 & ZP01 & $00: 32: 49$ & $2018-05-22$ & 716 & SK-X5 & 102269239 \\
\hline 16 & 3000385003 & PRODUKT 35 & ZP01 & 03:15:05 & $2018-05-22$ & 704 & SK-X5 & \\
\hline 17 & 3000391907 & PRODUKT 78 & ZP01 & $03: 33: 16$ & $2018-05-22$ & 14700 & SK-X4 & 100344581 \\
\hline 18 & 3000392818 & PRODUKT 1 & ZP01 & $04: 28: 10$ & $2018-05-22$ & 394 & SK-X3 & 106008395 \\
\hline 19 & 3000391683 & PRODUKT 21 & ZP01 & $05: 30: 45$ & $2018-05-22$ & 20575 & SK-X1 & 102148485 \\
\hline 20 & 3000391228 & PRODUKT 97 & ZP01 & $05: 40: 37$ & $2018-05-22$ & 3968 & SK-X2 & 102019846 \\
\hline 21 & 3000392664 & PRODUKT 1 & ZP01 & $09: 42: 31$ & $2018-05-22$ & 7200 & SK-X3 & 102549309 \\
\hline 22 & 3000393368 & PRODUKT 33 & ZP01 & $09: 44: 46$ & $2018-05-22$ & 2952 & SK-X3 & 105644816 \\
\hline 23 & 3000391801 & PRODUKT 32 & ZP01 & $09: 47: 32$ & $2018-05-22$ & 941 & SK-X2 & 102021071 \\
\hline 24 & 3000391206 & PRODUKT 23 & ZP01 & $09: 53: 14$ & $2018-05-22$ & 9809 & SK-X1 & 98353704 \\
\hline 25 & 3000388657 & PRODUKT 38 & ZP01 & $12: 17: 09$ & $2018-05-22$ & 14388 & SK-X5 & 102468278 \\
\hline 26 & 3000391684 & PRODUKT 10 & ZP01 & $13: 58: 12$ & $2018-05-22$ & 11599 & SK-X1 & 105616706 \\
\hline
\end{tabular}

Fig. 9. Data base of completed orders.

Source: own elaboration.

\section{FTP REPORT APPLICATION - CASE STUDY}

Figure 10 presented below shows a screenshot of the CROPPE Report prepared with use of FTP Report application (tab "8. FTP"). This sheet is called FTP Report and contains data in columns sequentially from the left:

- The order number (planned or process, planned will appear only if the order was in the production plan but was not executed or converted to process order);

- Material number;

- Material description;

- The production line on which the order was to be executed;

- The number of pieces in the order included in the production plan;

- The number of pieces made in the order;

- Tolerance, which is the percentage ratio of the quantity done to planned;

- The algorithm "extra-planned order?" giving a value of 1 for an executed order that is not included in the production plan;

Bartoszewicz G, Wdowicz M., Automation of The Process of Reporting the Compliance of the Production Plan with Its Execution Based on Integration of Sap ERP System in Connection with Excel Spreadsheet and Vba Application [in:] Adamczak M. et al., Digitalization of Supply Chains, Spatium, Radom 2019, p. 101-116. https://doi.org/10.17270/B.M.978-83-66017-86-3.8 
- The algorithm "not started?" giving a value of 1 for orders included in a production plan but not executed;

- The "Tolerance OK?" algorithm that values 1 for an order made in tolerance $(+/-10 \%)$;

- The end date of the order, if not completed, will be given the planned date of completion (date from the production plan);

- Similarly to the date above, the end time.

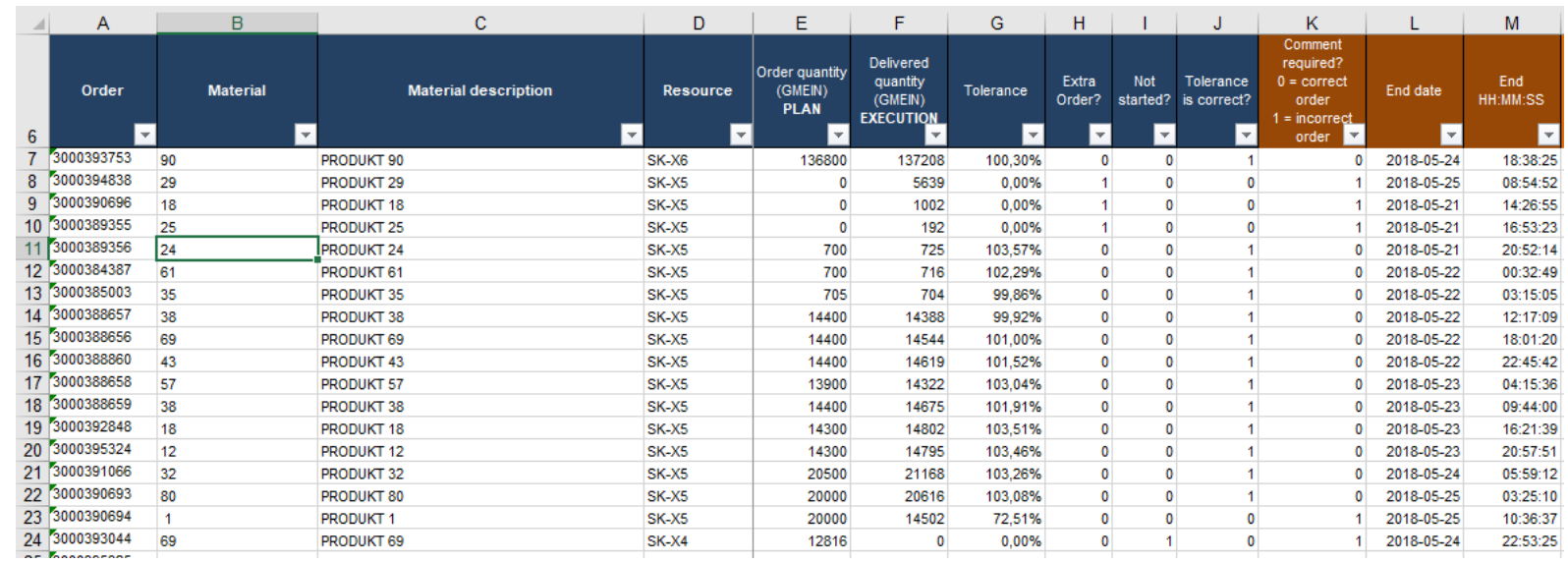

Fig. 10. FTP Report (columns A do M).

Source: own elaboration.

The K column of the report contains the "required comment?" algorithm. It indicates a value of 0 for the completed orders, which meet each of the following conditions:

1. The order is not over planned and was included in the production plan (algorithm "extraplanned order" $=0$ );

2. The order was not skipped, was in the production plan and was executed (the algorithm "not Started" =0);

3. The order was executed in an accepted tolerance [+/-10\%]; (the "OK tolerance?" algorithm $=1)$.

Any order that does not meet the minimum of one of the above conditions shall be considered as non-compliant and assigned a value of 1 in column K. It is assumed that for such items the user must provide the source reason, so called "Root cause" and a corresponding comment to enrich the content entry as is presented in Extended FTP Report in Figure 11. The

Bartoszewicz G, Wdowicz M., Automation of The Process of Reporting the Compliance of the Production Plan with Its Execution Based on Integration of Sap ERP System in Connection with Excel Spreadsheet and Vba Application [in:] Adamczak M. et al., Digitalization of Supply Chains, Spatium, Radom 2019, p. 101-116.

https://doi.org/10.17270/B.M.978-83-66017-86-3.8 
following columns contain a space for commenting the information described in this Extended Report (columns N and O).

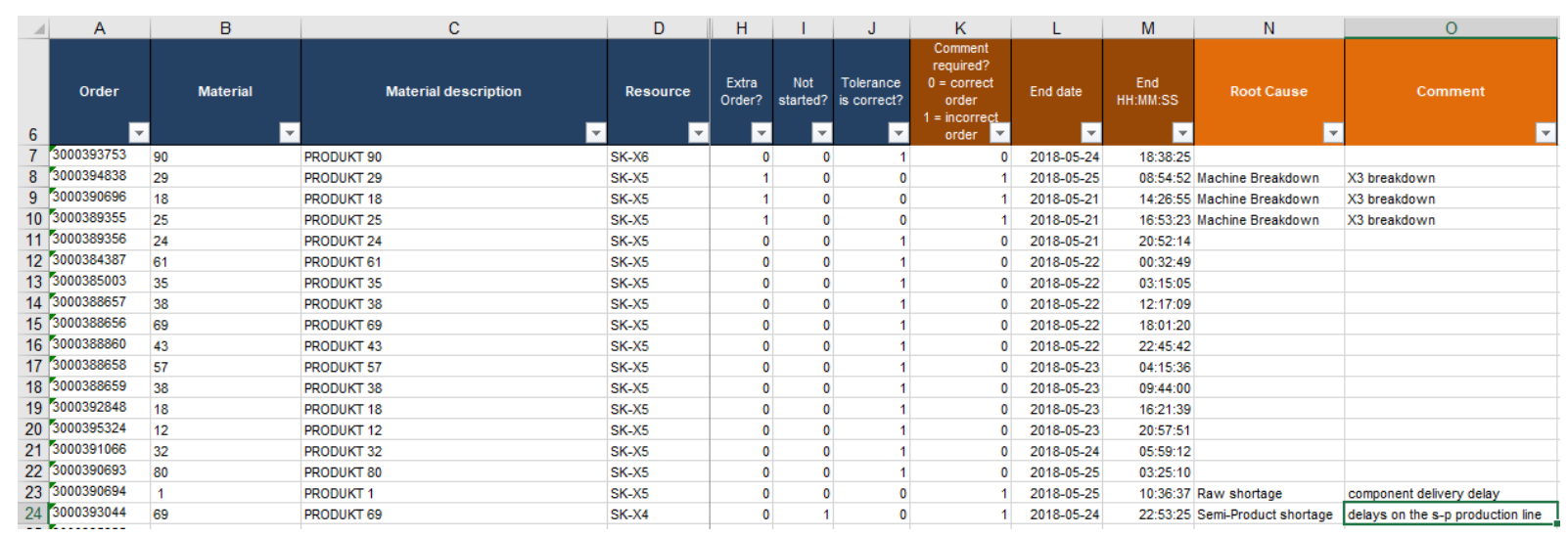

Fig. 11. Extended FTP Report.

Source: own elaboration.

In order to keep track of the reasons for the pending orders in the longer term, the possible source causes of their occurrence have been formalized and consolidated. The user can select one of the following categories from the drop down list:

- Lack of raw materials,

- Machinery failure,

- Low machine performance,

- Machine regulation,

- Absences on production,

- No semi-finished products,

- Qualitative mismatch,

- Incorrect data on the system.

By using unified root causes, the user receives the information that is relevant to the question why production plans are not executed according to their assumptions.

\section{CONCLUSIVE REMARKS}

The FTP Report is an example of a highly automated application that supports production logistics processes. The formalized methodology for counting the FTP indicator, indicates how

Bartoszewicz G, Wdowicz M., Automation of The Process of Reporting the Compliance of the Production Plan with Its Execution Based on Integration of Sap ERP System in Connection with Excel Spreadsheet and Vba Application [in:] Adamczak M. et al., Digitalization of Supply Chains, Spatium, Radom 2019, p. 101-116. https://doi.org/10.17270/B.M.978-83-66017-86-3.8 
much production is in line with the predetermined plan. This is a major support for production planning in the context of research on the stability of plans and production line efficiency. In addition, the application is an example of the use of automation activities under SAP ERP and Microsoft Excel using the SAP script recorder and the VBA programming language. Manual retrieval of data from SAP ERP system, apart from the fact that it absorbs a lot of time, is heavily exposed to human errors. The large number of fields to fill and the complex functionality of a transaction requiring specialized knowledge makes it easy to mistake. Automating the process of data retrieval, formatting and presenting allows to accelerate this entire reporting process from about 2 hours to 5 minutes. The application works flexibly so that it allows the user to change the time range or required production lines without data redownloading.

By tracking week to week results and indicating the main reasons for failed orders, the user is able to extract a group of production lines that are not production based as planned. In addition, he can determine why this happens and how the results will be affected, e.g. increased safety stock on hard to reach materials or replacing parts of machines that often suffer from accidents.

\section{REFERENCES}

Akhtar, J., 2015, Production Planning and Control with SAP ERP. Bonn: Rheinwerk Publishing, SAP PRESS.

Alexander M., Kusleika D., 2016, Microsoft Excel 2016 PL. Programowanie w VBA. Vademecum Walkenbacha, Wydawnictwo Helion, Gliwice.

Auksztol J., Balwierz P., Chomuszko M., 2011, SAP. Zrozumieć system ERP, Wydawnictwo Naukowe PWN, Warszawa.

Chapman Stephen N., 2006, The Fundamentals of Production Planning and Control. Pearson Prentice Hall, New Jersey.

Dickersbach J.,T., Keller G., 2011, Production Planning and Control with SAP ERP (2nd Edition). SAP PRESS, Galileo Press Inc., Boston (MA).

Bartoszewicz G, Wdowicz M., Automation of The Process of Reporting the Compliance of the Production Plan with Its Execution Based on Integration of Sap ERP System in Connection with Excel Spreadsheet and Vba Application [in:] Adamczak M. et al., Digitalization of Supply Chains, Spatium, Radom 2019, p. 101-116. https://doi.org/10.17270/B.M.978-83-66017-86-3.8 
Erwan P., 2017, Business Process Improvement Begins with BPR. Available on the Internet: https://blogs.sap.com/2017/07/13/business-process-improvement-begins-with-bpr/ (01/09/2019).

Schulz O., 2017, Using SAP. An Introduction for Beginners and Business Users. Bonn: Rheinwerk Publishing, SAP PRESS.

MB51, n.d., SAP MB51 - Material Document List, Available on the Internet: http://sap.beatexcel.com/2016/08/24/sap-mb51-material-document-list/ (01/09/2019).

Introduction-SAP PP, n.d., Introduction to SAP PP (Production Planning), Available on the Internet: https://guru99.com/introduction-sap-pp.html (01/09/2019).

COOISPI, n.d, Using COOISPI for MRP Checking, Available on the Internet: https://saphelper.wordpress.com/2016/03/23/using- cooispi-for-mrp-checking/ (01/09/2019).

Bartoszewicz G, Wdowicz M., Automation of The Process of Reporting the Compliance of the Production Plan with Its Execution Based on Integration of Sap ERP System in Connection with Excel Spreadsheet and Vba Application [in:] Adamczak M. et al., Digitalization of Supply Chains, Spatium, Radom 2019, p. 101-116. https://doi.org/10.17270/B.M.978-83-66017-86-3.8 